\title{
A extensão universitária durante a pandemia do coronavírus: experiências educomunicativas do curso de Comunicação Social da UFPE
}

Diego Gouveia Moreira Jornalista e professor do Núcleo de Design e Comunicação do Centro Acadêmico do Agreste da Universidade Federal de Pernambuco (UFPE)

E-mail: diego.moreira@ufpe.br

Sheila Borges de Oliveira

Jornalista e professora do Núcleo de Design e Comunicação do Centro Acadêmico do Agreste da UFPE.

E-mail: sheila.boliveira@ufpe.br

Giovana Borges Mesquita

Jornalista e professora do Programa de Pós-graduação em Comunicação da UFPE e do Núcleo de Design e Comunicação do Centro Acadêmico do Agreste da mesma instuição.

E-mail: giovana.mesquita@ufpe.br

Resumo: Este artigo tem como objetivo problematizar os projetos de extensão desenvolvidos durante a pandemia da Covid-19 por professoras do curso de Comunicação Social, integrantes do Núcleo de Design e Comunicação do Centro Acadêmico do Agreste, campus da Universidade Federal de Pernambuco em Caruaru. Para a elaboração do artigo, optamos pela revisão bibliográfica e pelo relato de experiência. A pesquisa analisa três projetos: "Rádio Cordel: na frequência do Agreste"; "Radionovela: literatura nas ondas do rádio" e "Solte sua voz: os invisíveis midiáticos". Por fim, concluímos que os projetos de extensão são compreendidos como experiências educomunicativas relevantes porque democratizam a
Abstract: Our article seeks to discuss extension projects developed by professors from the Social Communication undergraduate course, from the Design and Communication Center, from the Centro Acadêmico do Agreste, a campus of the Universidade Federal de Pernambuco in Caruaru, state of Pernambuco, during the Covid-19 pandemic. For the development of the paper, we opted for a bibliographic review and an experience report. Our study analyzes four extension projects: "Rádio Cordel: na frequência do Agreste"; "Radionovela: Literatura nas ondas do rádio" and "Solte sua voz: os invisíveis midiáticos". Finally, extension projects are understood as relevant educative communicative experiences because they democratize communication,
Recebido: $18 / 09 / 2020$

Aprovado: 12/11/2020 
comunicação, contribuem para a educação da comunidade universitária e formam os alunos que os produzem em experiências comunicacionais contemporâneas.

Palavras-chave: extensão; UFPE; comunicação social; educomunicação; democratização da comunicação. contribute to the education of university community and train the students involved in contemporary communicational experiences.

Keywords: extension; UFPE; social communication; educommunication; democratization of communication.

\section{INTRODUÇÃO}

Em função da pandemia da Covid-19, a Universidade Federal de Pernambuco (UFPE) suspendeu as aulas presenciais no dia 16 de março de 2020, mantendo, contudo, as atividades que poderiam ser realizadas remotamente, como as de extensão e pesquisa, desde que a segurança de professores, estudantes e técnicos envolvidos fosse garantida ao evitar aglomeração de pessoas e, consequentemente, a disseminação do novo coronavírus. Diante disso, a coordenação de três projetos de extensão, desenvolvidos por professores e estudantes do curso de Comunicação Social do Centro Acadêmico do Agreste (CAA), campus da UFPE em Caruaru e apresentados neste artigo, deu continuidade às ações extensionistas durante o período de suspensão das atividades presenciais.

Segundo o Fórum de Pró-reitores de Extensão das Instituições Públicas de Educação Superior Brasileiras, a extensão universitária pode ser definida:

[...] sob o princípio constitucional da indissociabilidade entre ensino, pesquisa

e extensão, [como um] processo interdisciplinar, educativo, cultural, científico e político que promove a interação transformadora entre Universidade e outros setores da sociedade ${ }^{1}$.

Dessa forma, a extensão é um processo regido pela interação dialógica, no qual universidade e setores sociais trocam saberes, impactando na formação dos estudantes e na sociedade. Sob esse princípio, os projetos "Rádio Cordel: na frequência do Agreste", "Radionovela: literatura nas ondas do rádio" e "Solte sua voz: os invisíveis midiáticos" foram realizados remotamente durante o período de quarentena determinado pela UFPE.

As iniciativas de extensão mobilizaram discentes que têm acesso, em suas casas, a computadores, tablets e celulares conectados à internet, para realizar o trabalho à distância. Assim, as coordenadoras das equipes buscaram integrar o grupo ao trabalho remoto a partir da criação de uma nova rotina adaptada ao distanciamento físico. Mesmo virtualmente, o objetivo era manter o grupo unido, tentando amenizar o impacto da pandemia na saúde física e mental dos estudantes com a suspensão das ações presenciais.

Duas dessas iniciativas apresentam como ponto em comum o rádio como mídia principal. A escolha dessa mídia se deu pela possibilidade de mobilidade, pelo baixo custo de produção e pelo consumo por diversos públicos.

1. FÓRUM DE PRÓ-REITORES DE EXTENSÃO DAS INSTITUICQÕES PÚBLICAS DE EDUCAÇÃO SUPERIOR BRASILEIRAS. Política Nacional de Extensão Universitária. Recife: Editora Universitária UFPE, 2013. p. 42. 
2. MOURA, João Benvindo de; LACERDA, Naziozênio Antônio (org.). Relatos de experiência: leitura e produção de textos no Parfor/UFPI. Teresina: EDUFPI, 2016.

3. FREIRE, Paulo. Pedagogia do oprimido. 18 . ed. Rio de Janeiro: Paz e Terra, 1988.

4. FREITAS, José Vicente. Educomunicação: contextualizando o processo de atribuição de sentidos e significados no delineamento do conceito. Revista Brasileira de Educação Ambiental, Diadema, v. 10, n. 2 2015, p. 149-162. Disponível em: https://periodicos.unifesp.br/index.php/revbea/ article/view/2072/1374 Acesso em: 28 out. 2020.

5. Ibidem, p. 150.

6. MEDITSCH, Eduardo. Paulo Freire nas práticas emancipadoras da comunicação: ainda hoje um métdodo subutilizado no Brasil. Revista Latinoamericana de Ciencias de la Comunicación, São Paulo, v. 13, n. 25,2016, p. $132-43$ Disponível em: http://revista.pubalaic.org/index.php/ alaic/article/view/850/450. Acesso em: 7 out. 2020.

7. SOARES, Ismar de Oliveira. Educom. Rádio, na trilha de Mario Kaplún. In: MARQUES DE MELO, José et al. (org.). Educomídia, alavanca da cidadania: legado utópico de Mario Kaplún. São Bernardo do Campo: Cátedra Unesco: Universidade Metodista de São Paulo, 2006.
Para o desenvolvimento dessas iniciativas, foram empregados métodos de um campo de intervenção social situado na inter-relação entre a comunicação social e a educação: a educomunicação. Uma das principais características desses projetos é uma educação em comunicação que beneficia a cidadania e o exercício de direitos já assegurados legalmente.

Este artigo tem como objetivo entender esses projetos, que se consolidaram como uma experiência educomunicativa, e apresentar os produtos gerados a partir dessas iniciativas num momento em que se vive a maior crise sanitária do século XXI. Optou-se pela revisão bibliográfica e pelo relato de experiência - a última, uma metodologia muito comum na área da educação e saúde. O relato da experiência é utilizado para descrever e dar publicidade a intervenções e seus resultados, destacando a integração entre teoria e prática envolvida na intervenção ${ }^{2}$. A relevância do relato está na sua pertinência e importância dos resultados que a intervenção produziu.

\section{A EDUCOMUNICAÇÃO COMO PRÁTICA PEDAGÓGICA EFICAZ}

Pesquisadores da educação defendem, cada vez mais, uma educação que emancipe os indivíduos de forma que haja um protagonismo por meio de métodos dialógicos, em oposição ao modelo educacional no qual se observa a mera transmissão de informações na relação educador-educando. Essas ideias foram bastante compartilhadas no Brasil a partir das práticas adotadas por Paulo Freire, que acreditava na plena comunicação baseada em uma consciência educativa crítica. O pesquisador também defendia uma educação globalizante pela instrumentalização comunicativa e considerava as duas coisas mutuamente complementares ${ }^{3}$.

A utilização da comunicação como ferramenta pedagógica é uma prática que também remonta a Paulo Freire, que, já na década de 1960, anunciava que a educação estaria cada dia mais interligada à comunicação ${ }^{4}$.

A junção das duas áreas - educação e comunicação - criou um novo campo de saber e é essencial para que ocorram transformações e mudanças sociais de fato, pois "esses dois campos associados possibilitam a democratização da informação, da cultura e do conhecimento, contribuindo assim para uma construção social baseada na cidadania" .

De acordo com Meditsch,

O estudo das ideias de Freire e de sua aplicação na prática da mídia pode ser caminho para a construção concreta de alternativas a um sistema midiático orientado somente pela lógica de mercado, ainda mais quando parecem estar dadas as condições tecnológicas para tanto ${ }^{6}$.

Além de Freire, Célestin Freinet e Jesús Martín-Barbero também são analisados pelos estudiosos da educomunicação como fundadores da proposta que congrega a comunicação e a educação. Entretanto, foi o argentino Mário Kaplún o primeiro a se referir ao campo ${ }^{7}$. 
Como bem destaca Freitas, Kaplún foi responsável por "trazer contribuições de diversos ramos do conhecimento humano como parte integrante da

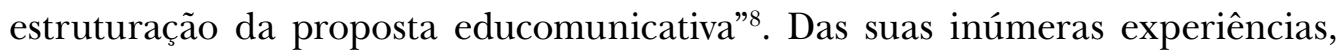
duas têm uma relevância grande para se refletir sobre a relação educação e comunicação: o método de leitura crítica e o método do Cassette-Foro.

Ao olhar especialmente para o rádio no livro Producción del programas de rádio: el guión, la realización, "Kaplún mostrava-se preocupado em propor algo mais que uma teoria, ele queria estudar e apontar soluções viáveis para o cenário de uma América Latina de iletrados"9.

Com base nas contribuições de Freire e Kaplún, Ismar de Oliveira Soares deu continuidade aos estudos sobre o tema e foi o responsável por dar um novo significado à educomunicação com a pesquisa realizada pelo Núcleo de Comunicação e Educação da USP (NCE) entre 1997 e 1999. Nesta experiência, o termo foi definido da seguinte maneira:

Toda experiência de envolvimento dos agentes sociais, suas empresas e organizações, na implementação de ações voltadas para o planejamento e desenvolvimento de ecossistemas comunicativos abertos, democráticos e participativos, tendo como meta a promoção da cidadania mediante o exercício da expressão comunicativa, possibilitada pela mediação tecnológica e pelo acesso e gestão democrática dos recursos da informação ${ }^{10}$.

Para Soares ${ }^{11}$, estão entre os princípios da educomunicação: (1) promover o acesso democrático à produção e à difusão de informação; (2) facilitar a percepção crítica da maneira como o mundo é editado nos meios; (3) facilitar o ensino/aprendizado por meio do uso criativo dos meios de comunicação; e (4) promover a expressão comunicativa dos membros da comunidade em questão.

Assim, em uma primeira investigação sobre as práticas desenvolvidas durante a execução dos projetos de extensão, sobretudo durante a pandemia da Covid-19, pelo curso de Comunicação Social do Centro Acadêmico do Agreste da UFPE, pode-se perceber a existência de um ecossistema favoravelmente comunicativo. $\mathrm{O}$ conceito de educomunicação se relaciona à ideia de ecossistema comunicativo quando se compreende que ela é representada pelo conjunto de ações que permitem que educadores, comunicadores e outros agentes promovam e ampliem as relações de comunicação entre as pessoas que compõem a comunidade educativa. Isto significa dizer que o foco da ação educomunicativa são os ecossistemas comunicativos, que devem conter fluxos comunicativos positivos.

Nos estudos de Soares $^{12}$, há uma recomendação expressa de que, ao gerir os fluxos comunicacionais, é importante começar a partir dos pontos de consenso para evitar conflitos. Esse modo de ver a comunicação tem a ver com a perspectiva de compartilhar, trocar e de formar entendimento entre as pessoas. Nesse sentido, essa reflexão se aproxima da visão de teóricos da educação, como Paulo Freire, que considera a comunicação como sendo fundamental nas relações humanas. $\mathrm{O}$ educador acredita que, para existir conhecimento, é necessária, como premissa, uma relação social igualitária e dialogal entre os sujeitos. Isso, para Freire, é que resulta em uma prática

8. FREITAS, 2015, p. 153.

9. Ibidem, p. 154. 10. SOARES, 2006, p. 179 11. SOARES, Ismar de Oliveira. Metodologias da Educação para a Comunicação no Brasil e na América Latina. In: BACCEGA, Maria Aparecida. Gestão de processos comunicacionais. São Paulo: Atlas, 2002. p. 113-132. 12. Ibidem. 
13. GUTIERREZ, Francisco. Linguagem Total: uma pedagogia dos meios de comunicação. São Paulo: Summus, 1978

14. SOARES, Ismar de Oliveira. Educomunicação: um campo de mediações. Comunicação \& Educação, São Paulo, ano 7, n. 19., p. 12-24, 2000.

15. LIMA, Venício Artur de. Mídia: Teoria e Política. São Paulo: Fundação Perseu Abramo, 2000. p. 69. social transformadora. Francisco Gutierrez, a partir das ideias de Paulo Freire, defende o princípio de que o "processo de comunicação é essencial à educação" e que "o processo de aprendizagem é autêntico quando se efetua uma mudança naquele que aprende. Por esse motivo, a aprendizagem pressupõe a interação, o intercâmbio"13.

A educomunicação, então, reúne ações inerentes ao planejamento, à implementação e à avaliação de processos, programas e produtos destinados a criar e fortalecer ecossistemas comunicativos em espaços educativos presenciais ou virtuais, tais como escolas, centros culturais, emissoras de rádio e TVs educativas, centros produtores de materiais educativos analógicos e digitais, centros de coordenação de educação a distância ou e-learning, entre outros ${ }^{14}$.

Dessa forma, é possível entender que os ambientes não-escolares também se configuram como espaços educativos, uma vez que eles podem favorecer os processos de construção de conhecimentos, embora fora dos padrões didáticos propostos tradicionalmente. Também, pode-se afirmar que, ao criar produtos, a exemplo dos surgidos nos projetos de extensão desenvolvidos por professores e estudantes do curso de Comunicação Social, é possível proporcionar a existência de um ambiente que propicie a implementação de tais práticas educomunicativas.

A teoria dialógica de Freire, baseada em colaboração, união, organização e síntese cultural, é citada, até hoje, como uma prática que se aproxima do conceito de educomunicação. Acreditando que a educomunicação se configura como um novo campo teórico-prático que é integrado e, ao mesmo tempo, proporciona a integração e pressupondo uma dinâmica de funcionamento que reconfigura a relação entre comunicação e educação, Lima afirma que:

No momento em que as potencialidades das tecnologias interativas acenam para a quebra da unidirecionalidade e da centralização das comunicações, o conceito de comunicação dialógica, relacional e transformadora de Freire oferece uma referência normativa revitalizada, criativa e desafiadora para todos aqueles que acreditavam na prevalência de um modelo social comunicativo humano e libertado ${ }^{15}$.

Isso faz com que os pesquisadores, comunicólogos e educadores busquem incansavelmente "definições", "direcionamentos" acerca do papel dos meios de comunicação social na sociedade. Tal cenário é visualizado em algumas produções veiculadas a diversos públicos por meio de um dialogismo participativo, libertário, defendido intensamente pelo educador Paulo Freire como algo intimamente ligado à educação.

Os comunicólogos socialmente comprometidos com esses princípios vêm, a cada dia, ocupando os campos acadêmicos com o objetivo de refletir e debater sobre o que cabe aos meios de comunicação, especialmente em um cenário de convergência midiática com lançamento de conteúdos em múltiplas plataformas de mídia. As práticas educomunicativas são potencializadas nesse cenário como será visto a partir dos projetos desenvolvidos no curso de Comunicação Social do Centro Acadêmico do Agreste da UFPE. 


\section{RÁDIO CORDEL: NA FREQUÊNCIA DO AGRESTE}

A Rádio Cordel foi criada em 2018 para ser uma rádio comunitária que funcionasse como rádio-poste, dentro das dependências do CAA, e na internet, por meio de podcast. Ela promove uma prestação de serviços à comunidade, apresentando as ações desenvolvidas por professores, estudantes e técnicos do CAA. Este projeto de extensão está vinculado a ações de ensino e pesquisa do curso de Comunicação Social do CAA.

A programação e os gêneros radiofônicos elaborados para a grade da Cordel tomaram como ponto de partida os estudos dos formatos mais tradicionais, apontados por Prado ${ }^{16}$, e das adaptações para a webrádio, com base em Prata ${ }^{17}$. Isso porque, antes da quarentena, já desenvolvíamos produtos para a rádio tradicional em função das parcerias firmadas com as rádios universitárias da UFPE, a Paulo Freire e a Universitária FM, e para o site do projeto, por meio da disponibilização de podcast ancorados em plataformas de mídias sonoras, como o Spotify.

Com a pandemia da Covid-19, a programação da Cordel foi adaptada ao trabalho remoto e os estudantes puderam colocar em prática o que tinham aprendido em sala de aula e nas orientações passadas pelas coordenadoras do projeto, apesar das limitações por não terem o suporte dos laboratórios utilizados. Nesse sentido, fizemos o que Kischinhevsky ${ }^{18}$ chama rádio expandido, um conceito elaborado por ele para sinalizar que o rádio chega às mídias sociais em função da própria capacidade de ubiquidade da internet. Assim, os programas da Rádio Cordel nas temporadas da pandemia transbordaram as ondas hertzianas do dial e foram para as redes e mídias sociais. Passaram a ser acompanhados por diversas plataformas sem as limitações físicas da rádio analógica, como iremos descrever mais à frente.

Nesse contexto, o processo educacional emancipatório foi observado quando os 24 estudantes assumiram o protagonismo das ações de produção, gravação, edição e divulgação dos programas, dialogando diretamente com as comunidades que eram atendidas. Eles, inclusive, realizaram oficinas para compartilhar o conhecimento com os alunos recém ingressos no curso de Comunicação Social e com discentes de outros cursos de graduação que também produziam podcasts.

O ecossistema comunicativo sempre caminhou por várias direções de forma dialógica e transparente com canais abertos para dentro da UFPE e para fora em sintonia com a sociedade por meio das redes sociais e de grupos do WhatsApp, o que se ampliou para diversas plataformas de mídias sonoras na pandemia; tudo isso com o objetivo de promover o acesso plural à produção e difusão da informação.

As abordagens temáticas das temporadas da Cordel foram planejadas com a participação de todos os atores envolvidos e em sintonia com as comunidades atendidas pelos programas, principalmente de Caruaru e cidades da região Agreste. Em função disso, todos os temas das quatro temporadas foram decididos a partir da prática da escuta das demandas do grupo e, também, dos anseios do(a) cidadão(ã).
16. PRADO, Magaly. Produção de rádio: um manual prático. Rio de Janeiro: Elsevier, 2006.

17. PRATA, Nair. Webradio: novos gêneros, novas formas de interação. Florianópolis: Insular, 2012.

18. KISCHINHEVSKY, Marcelo. Rádio e mídias sociais: mediações e interações radiofônnicas em plataformas digitais de comunicação. Rio de Janeiro: MauadX, 2016. 
Entre abril e setembro, foram veiculadas três temporadas. A primeira circulou no período de abril e maio, reunindo 24 programas de até 10 minutos sobre as ações de enfrentamento, por parte da UFPE, à Covid-19, além de registros de como integrantes do CAA e moradores de cidades do Agreste pernambucano estavam sobrevivendo à quarentena. Os episódios, veiculados três vezes por semana, trataram de temas como a vivência de estar longe de casa e do país, o trabalho na quarentena, a ajuda dada aos pequenos comerciantes, o cuidar dos filhos, o impacto no turismo e na publicidade, a prática dos estudantes de medicina, a volta à casa dos pais, a produção e doação de protetores faciais e álcool gel e a importância da alimentação e da assistência psicológica.

A segunda temporada da Cordel veiculou uma série de programas, às terças e sextas-feiras, para mostrar que a cultura dos festejos juninos continuou forte em Caruaru, mesmo sem a tradicional festa de rua. Durante o mês de junho de 2020, foram veiculados "programetes" de até cinco minutos. Relembrando a magia da época, eles trouxeram as "Crônicas Cantadas do País do São João", histórias autorais produzidas pelos estudantes sobre as festas que fazem de Caruaru a Capital do Forró.

Durante as sextas-feiras, foram compartilhados programas de 25 minutos para estimular a memória afetiva do ciclo junino. Os dois primeiros programas recordaram os festejos nos anos 1990 com o resgate de músicas e comemorações da época. Já os dois programas restantes focaram no contexto atual, no qual a festa teve que se reinventar por causa da pandemia da Covid-19.

A terceira temporada foi veiculada entre julho e setembro e direcionada para a discussão de como a arte pode ajudar a manter a saúde mental num período de quarentena prolongada. Foram produzidos 11 programas de 25 minutos com experiências coletivas e individuais dos estudantes envolvidos no projeto sobre expressões artísticas como a fotografia, o cinema, a literatura, a música, a televisão, os jogos, o desenho, a moda, o artesanato, as artes plásticas, o teatro e a dança. A quarta temporada será executada entre outubro e dezembro para registrar as memórias da quarentena de cidadãos(ãs) moradores do Agreste pernambucano.

Os programas das temporadas contemplaram as etapas de produção, definidas por McLeish ${ }^{19}$ e Prado ${ }^{20}$, classificadas em produção executiva, pré-produção, produção em andamento e pós-produção. Na produção executiva, o projeto das temporadas foi esboçado. Na etapa de pré-produção, as informações necessárias para os programas foram coletadas. Na produção em andamento, o programa foi realizado. Essa etapa se estende da produção do conteúdo até a veiculação do material.

Na produção das reportagens, os repórteres entrevistaram as pessoas pelo

19. MCLEISH, Robert. Produção de rádio: um guia abrangente de produção radiofônica. São Paulo: Summus, 2001.

20. PRADO, 2006. WhatsApp. Em seguida, escreveram o roteiro e o script. Na sequência, enviavam para os coordenadores da produção, que solicitavam os ajustes necessários. Depois de feitos os ajustes, os repórteres usando os gravadores de seus celulares, faziam a gravação do texto. Os arquivos, então, eram enviados para a equipe de edição, juntamente com os trechos das entrevistas selecionadas. A edição foi 
feita em programas gratuitos baixados nos computadores pessoais da equipe. Depois da edição, o programa finalizado é encaminhado à equipe de divulgação da rádio, que distribui o conteúdo por meio de site, das redes sociais, de grupos de WhatsApp e das plataformas de streaming de música ${ }^{21}$.

Todo o grupo contribui com a fase de pós-produção, catalogando o material produzido para que possamos fazer, rotineiramente, os relatórios do que foi realizado. Ao adaptar a grade de programação da Cordel ao trabalho remoto na pandemia da Covid-19, a equipe procurou atender os princípios da educomunicação, promovendo o acesso democrático à informação, proporcionando uma reflexão sobre o mundo editado pela mídia corporativa e efetivando o diálogo entre ensino e aprendizado com o uso criativo das mídias sociais.

O produto foi divulgado pelas Rádios Universitária FM e Paulo Freire AM, ambas vinculadas à UFPE, além da rádio pública Frei Caneca, no Recife, e da comunitária Lider FM, em Toritama, no Agreste do Estado. A programação ainda foi veiculada pela Rádio da Universidade de Ouro Preto, em Minas Gerais.

\section{RADIONOVELA: LITERATURA NAS ONDAS DO RÁDIO}

Nesse cenário da pandemia, outro projeto do curso de Comunicação Social da UFPE de Caruaru resolveu apostar na literatura para chamar atenção para a necessidade de prevenção. $\mathrm{O}$ projeto "Radionovela: literatura nas ondas do rádio", surgido em 2018, assumiu o desafio de fazer uma radionovela envolvendo uma equipe de produção de sete pessoas el4 radioatores e radioatrizes coordenada por duas professoras e com produção toda feita de casa. Assim surgiu a radionovela Auto da Compadecida em Tempos de Pandemia, uma adaptação da obra de Ariano Suassuna, produzida por estudantes dos cursos de Comunicação Social e Design da UFPE, campus Caruaru.

Apesar de trabalhar com uma das obras mais conhecidas do escritor paraibano, Ariano Suassuna, a coordenação do projeto procurou colocar na adaptação discussões sobre o coronavírus (incluindo na história, o Capitão Covid), fake newws, além de questões econômicas e políticas que dificultam a eficácia do distanciamento físico. A preocupação era que o texto, embora adaptado, continuasse fiel e mantendo as características do teatro popular, mas "atualizado", mostrando o Brasil em 2020, onde milhares de pessoas em vulnerabilidade social morrem diariamente pela falta de ação do poder público em meio a uma pandemia.

A radionovela, dividida em nove episódios, foi adaptada, gravada e veiculada entre os dias 6 de maio e 4 junho de 2020. Junto à produção sonora, foram elaboradas estratégias para as redes sociais, cujo uso foi pensado não só para divulgar o conteúdo entre os jovens, público-alvo da radionovela como também com o intuito de buscar uma interatividade, feita por meio de enquetes, posts interativos e da provocação para que deixassem seus comentários nos textos publicados no feed a cada veiculação de um novo episódio.

O processo de criação do texto de adaptação do Auto da Compadecida para a inclusão da temática da Covid-19 foi feito com a inserção de, pelo menos, três

21. A Rádio Cordel pode ser ouvida pelas plataformas de streaming Spotify, Radio Públic, Pocket Casts, Overcast, Google Podcasts, Breaker e Anchor. Também está no Instagram, por meio do perfil @radiocordel, no Facebook da Aveloz, agência experimental de comunicação da UFPE, e no site www.radiocordel.ml, além da presença em grupos de WhatsApp. 
personagens que não constavam na obra original: o Capitão Covid, o prefeito de Taperoá e o jornalista. O Capitão Covid, que substitui o Capitão Severino de Aracaju, personagem da obra original, foi colocado na radionovela como um justiceiro que vem cobrar dos poderosos as ações que tanto impactam o meio ambiente, causando a morte de milhares de pessoas.

A entrada do prefeito Teobaldo, um cumpridor de ordens do major Antônio Moraes, é uma crítica a alguns governantes que não assumem sua responsabilidade no controle da pandemia. Já a incorporação do jornalista na adaptação teve a intenção de chamar a atenção para o papel do jornalismo em uma sociedade democrática, mostrando o quanto é importante a população buscar fontes confiáveis de informação, evitando cair no perigo da circulação de fake news. O jornalista também teve o papel de conscientizar para cuidados como lavar as mãos e ficar em casa.

A cada capítulo, buscou-se fazer referências ao que estava acontecendo no Brasil no momento da pandemia. A produção do Auto da Compadecida em tempos de pandemia não se resumiu a criação e veiculação da radionovela. Além do produto, foram criadas trilhas, um site para divulgação do projeto, conteúdos gráficos e textuais e, por fim, espaços em redes sociais, numa perspectiva de que a audiência pudesse interagir com a equipe responsável pela produção da radionovela. A veiculação em rádios educativas e públicas, por exemplo, as rádios Universitária, Paulo Freire, ambas da UFPE; Frei Caneca, da Prefeitura do Recife; a Rádio UFOP, da Universidade Federal de Ouro Preto; além de uma dezena de rádios comunitárias pernambucanas contribuiu para levar a mensagem para variados públicos. Junto a isso a utilização das redes sociais, como a página no Instagram (@radio.novela) e de plataformas de streaming, como Spotify, onde a radionovela pode ser encontrada pelo endereço Radionovela: literatura nas ondas do rádio, fez com que o conteúdo sonoro se expandisse, alcançando ouvintes de diversos estados do país e do mundo, a exemplo de países como Portugal, Espanha, França, Argentina e Alemanha.

No desenvolvimento do projeto "Radionovela: Literatura nas ondas do Rádio" estão evidenciados os princípios da educomunicação, ou seja: (1) a promoção do acesso democrático à difusão de informação; (2) a facilitação do ensino/ aprendizado por meio do uso criativo dos meios de comunicação; e (3) a promoção da expressão comunicativa dos membros da comunidade em questão.

O uso criativo dos meios de comunicação possibilitou um aprendizado conjunto para os estudantes de conseguir colocar, semanalmente no ar, duas vezes por semana, episódios que eram escritos, gravados, editados, montados e veiculados, trabalhando com uma equipe de 21 pessoas divididas em pelo menos 14 cidades diferentes. Numa superação de questões emocionais, visto que o momento atual de uma pandemia tem agravado quadro de saúde mental, e técnicos, uma vez que muitas dessas cidades sofrem com problemas, como a dificuldade de acesso à internet.

Por fim, outro ganho foi trabalhar com a equipe a incorporação de temas e elementos da realidade ao ficcional, sem descaracterizar a obra original, em 
um curto período. A coordenação do projeto tinha o entendimento de que, em um momento crítico de uma pandemia, não era possível fazer uma adaptação que buscasse só divertir. Era preciso chamar atenção para questões, além da própria pandemia, como o papel que o jornalismo desempenha numa sociedade democrática para as relações de poder na sociedade e para as fake news, tentando chegar principalmente ao público jovem.

\section{SOLTE SUA VOZ: OS INVISÍVEIS MIDIÁTICOS}

O Santos Conectados no Combate à Covid-19, uma produção multimídia do projeto de extensão "Solte sua voz: os invisíveis midiáticos", foi criado em junho de 2020 com o objetivo de alertar à população, sobretudo a de maior vulnerabilidade social, sobre a importância da prevenção, usando a festa junina tradicional do Nordeste brasileiro para orientar a população sobre os riscos do coronavírus.

No Nordeste, o mês de junho é marcado pela celebração de três importantes santos católicos: Santo Antônio, São João e São Pedro. Com a pandemia, os coordenadores do projeto de extensão "Solte sua voz: os invisíveis midiáticos", desenvolvido no curso de Comunicação Social da Universidade Federal de Pernambuco desde 2019, resolveram produzir produtos de comunicação incorporando esses santos juninos aos esforços de prevenção da Covid-19.

Um desses produtos é a radionovela Santos Conectados no Combate à Covid19, que teve quatro episódios. Na radionovela, os santos juninos se conectam com os fiéis através de conversas no aplicativo WhatsApp. Durante os diálogos, os santos reafirmam a importância de ficar em casa, manter o distanciamento físico e seguir os protocolos sanitários estabelecidos pelos órgãos de saúde.

Além do Spotify (Solte sua voz) e de outras plataformas de streaming, os episódios foram veiculados na Rádio Educativa Frei Caneca, emissora pública do Recife. A radionovela também foi cedida para veiculação nas rádios comunitárias vinculadas à Associação Brasileira de Rádios Comunitárias (Abraço).

Coordenado por duas professoras dos cursos de Comunicação Social e Medicina, a produção dos Santos conectados mobilizou oito estudantes dos cursos de Comunicação Social e de Design da UFPE, campus do Agreste. Realizado de maneira remota devido ao isolamento físico, a produção dos Santos Conectados foi dividida em quatro etapas: (1) a criação da radionovela, que contou com a produção de texto autoral, do script, da escolha e da direção dos radioatores; (2) a gravação, sonorização, edição do conteúdo e montagem; (3) a elaboração de uma história em quadrinhos, que teve a adaptação do texto da radionovela, a criação dos personagens, ilustração, edição e finalização; (4) a criação de cartazes com frases que traziam os Santos para o contexto da pandemia. Todas as atividades foram feitas a partir de casa dos estudantes, superando desafios técnicos, de acesso à internet, e questões de saúde. A cada veiculação de um episódio foram produzidos cards para as publicações no Instagram do projeto (@soltesuavozufpe) e divulgação no WhatsApp. 
Além de pensar a comunicação como direito, buscou-se, com o "Solte sua Voz na quarentena”, fortalecer seu papel educativo, concordando com Peruzzo ${ }^{22}$, que a participação direta no processo comunicativo ajuda a desenvolver pessoas:

o cidadão que passa a escrever para o jornalzinho; a falar no rádio; a fazer o papel de ator num vídeo popular; a criar, produzir e transmitir um programa de rádio ou de televisão; a discutir os objetivos, a linha editorial e os princípios de gestão do meio de comunicação; a selecionar conteúdos etc., vive um processo de educação informal em relação à compreensão da mídia e do contexto onde vive ${ }^{23}$.

Ainda de acordo com a autora, as relações entre educação e comunicação se explicitam, pois as pessoas envolvidas em tais processos desenvolvem o seu conhecimento e mudam o seu modo de ver e relacionar-se com a sociedade e com o próprio sistema dos meios de comunicação de massa. Apropriam-se das técnicas e de instrumentos tecnológicos de comunicação, adquirem uma visão mais crítica, tanto pelas informações que recebem, quanto pelo que aprendem através da vivência, da própria prática.

Dessa maneira, o "Solte Sua Voz" trabalha numa perspectiva de uma comunicação dialógica, contra-hegemônica e horizontal, o que pode contribuir na formação do estudante, que passa a realizar uma comunicação não mercadológica, como também busca uma transformação social na medida em que potencializa o protagonismo de vozes excluídas do cenário midiático hegemônico.

\section{CONSIDERAÇÕES FINAI}

O contexto da pandemia do novo coronavírus demandou adaptação das universidades para realização de suas atividades. Foi um momento importante para implementação de práticas educomunicativas na condução de iniciativas de extensão.

A partir de leituras sobre o tema e com os dados coletados dos projetos de extensão, é possível afirmar que as iniciativas "Rádio Cordel: na frequência do Agreste", "Radionovela: Literatura nas ondas do rádio" e "Solte sua voz: os invisíveis midiáticos" produzem práticas educomunicativas que contribuem para a educação em direitos humanos no rádio e na internet e têm fundamentos dialógicos. Foram encontradas evidências, durante o processo de elaboração, de que há a presença dos pressupostos definidos pelos pesquisadores da educomunicação, a exemplo da democratização da informação, o diálogo feito de forma horizontal, sem hierarquias, além de contribuições para o favorecimento ao exercício da cidadania.

Os sujeitos que produzem os projetos de extensão podem ser considerados educomunicadores, uma vez que a educomunicação aproxima a educação da comunicação, segundo o que define o termo a partir das experiências do professor Ismar de Oliveira Soares. Nos projetos, verificou-se, ainda, que os sujeitos admitem o erro como parte do processo de aprendizagem, lidam bem com as diferenças e a diversidade entre si e favorecem mais os processos educativos 
que os próprios produtos elaborados com suas práticas. A experiência também é transmidiática porque leva conteúdos de um suporte midiático para outros.

Os projetos se pautam nas diretrizes estabelecidas pela UFPE, sobretudo na interação dialógica, compreendida pela indicação de diálogo, de troca de saberes, de aliança com movimentos, setores e organizações sociais; e pela indissociabilidade ensino-pesquisa-extensão. Além da contribuição na formação do estudante, o maior impacto é a possibilidade de transformação social nas comunidades, na medida em que buscam trabalhar uma informação contra-hegemônica, atingindo o seu público-alvo através de diversas mídias.

\section{REFERÊNCIAS BIBLIOGRÁFICAS}

FREIRE, Paulo. Pedagogia do oprimido. 18. ed. Rio de Janeiro: Paz e Terra, 1988.

FREITAS, José Vicente. Educomunicação: contextualizando o processo de atribuição de sentidos e significados no delineamento do conceito. Revista Brasileira de Educação Ambiental, Diadema, v. 10, n. 2, 2015, p. 149-162. Disponível em: https://periodicos.unifesp.br/index.php/revbea/article/ view/2072/1374. Acesso em: 28 out. 2020.

GUTIERREZ, Francisco. Linguagem Total: uma pedagogia dos meios de comunicação. São Paulo: Summus, 1978.

KISCHINHEVSKY, Marcelo. Rádio e mídias sociais: mediações e interações radiofônicas em plataformas digitais de comunicação. Rio de Janeiro: Mauad $\mathrm{X}, 2016$.

LIMA, Venício Artur de. Mídia: Teoria e Política. São Paulo: Fundação Perseu Abramo, 2000.

MCLEISH, Robert. Produção de rádio: um guia abrangente de produção radiofônica. São Paulo: Summus, 2001.

MEDITSCH, Eduardo. Paulo Freire nas práticas emancipadoras da comunicação: ainda hoje um métdodo subutilizado no Brasil. Revista Latinoamericana de Ciencias de la Comunicación, São Paulo, v. 13, n. 25, 2016, p. 132-43. Disponível em: http://revista.pubalaic.org/index.php/ alaic/article/view/850/450. Acesso em: 7 out. 2020.

MOURA, João Benvindo de; LACERDA, Naziozênio Antônio (org.). Relatos de experiência: leitura e produção de textos no Parfor/UFPI. Teresina: EDUFPI, 2016.

Fórum de Pró-Reitores de Extensão das Instituições Públicas de Educação Superior Brasileiras. Política Nacional de Extensão Universitária. Recife: Editora Universitária UFPE, 2013. 
PERUZZO, Cícilia. Direito à Comunicação Comunitária, participação popular e cidadania. Lumina, Juiz de Fora, n. 1, v. 1, p. 1-29, 2007. Disponível em: https:/ / lumina.ufjf.emnuvens.com.br/lumina/article/view/201. Acesso em: 18 set. 2020.

PRADO, Magaly. Produção de rádio: um manual prático. Rio de Janeiro: Elsevier, 2006.

PRATA, Nair. Webradio: novos gêneros, novas formas de interação. Florianópolis: Insular, 2012.

SOARES, Ismar de Oliveira. Educomunicação: um campo de mediações. Comunicação \& Educação, São Paulo, ano 7, n. 19., p. 12-24, 2000.

SOARES, Ismar de Oliveira. Metodologias da Educação para a Comunicação no Brasil e na América Latina. In: BACCEGA, Maria Aparecida. Gestão de processos comunicacionais. São Paulo: Atlas, 2002. p. 113-132.

SOARES, Ismar de Oliveira. Educom.Rádio, na trilha de Mario Kaplún. In: MARQUES DE MELO, José et al. (org.). Educomídia, alavanca da cidadania: o legado utópico de Mario Kaplún. São Bernardo do Campo: Cátedra Unesco: Universidade Metodista de São Paulo, 2006. 